\title{
Use of Direct Oral Anticoagulants in Children and Adolescents
}

\author{
Manuela Albisetti ${ }^{1}$ \\ ${ }^{1}$ Division of Hematology and Children's Research Center, University \\ Children's Hospital, Zurich, Switzerland \\ Address for correspondence Manuela Albisetti, MD, Division of \\ Hematology, University Children's Hospital, Steinwiesstrasse 75, CH- \\ 8032 Zurich, Switzerland (e-mail: manuela.albisetti@kispi.uzh.ch). \\ Hämostaseologie 2020;40:64-73.
}

\begin{abstract}
Keywords

- direct oral anticoagulants

- anticoagulation

- children

- thrombosis

Zusammenfassung

Schlüsselwörter

- direkte orale Antikoagulantien

- Antikoagulation

- Kinder

- Thrombose

While the need for anticoagulation in children has increased over the last decades, dose regimens of currently used anticoagulants, including low-molecular-weight heparin $(\mathrm{LMWH})$ and vitamin $\mathrm{K}$ antagonist (VKA), are still extrapolated from adult guidelines because well-designed clinical trials were never performed in children. This approach is not optimal due to specific pediatric features of the hemostatic system and pathophysiology of thrombosis. These anticoagulants also present several disadvantages that further hamper optimal anticoagulation of pediatric patients, especially newborns and infants. The new direct oral anticoagulants (DOACs), which have the potential to overcome these disadvantages, were extensively investigated in adults and have become a valid alternative to LMWH and VKA for anticoagulation in the adult population. Several pediatric trials on all approved DOACs are currently ongoing, providing specific pediatric formulations and age- and weight-adjusted dose guidelines. First results of phase III trials indicate that DOACs are at least as efficient and safe as LMWH and VKA for the treatment and prevention of thrombotic events in children with different clinical conditions. This review article summarizes available data from terminated and ongoing controlled trials on DOACs in children and adolescents.

Während der Bedarf an Antikoagulation bei Kindern in den letzten Jahrzehnten zugenommen hat, werden die Therapierichtlinien der derzeit verwendeten Antikoagulantien, einschließlich niedermolekularem Heparin (LMWH) und Vitamin K-Antagonisten (VKA), immer noch aus den Empfehlungen für Erwachsene extrapoliert, da nie gut konzipierte klinische Studien an Kindern durchgeführt wurden. Dieser Ansatz ist aufgrund spezifischer pädiatrischer Merkmale des hämostatischen Systems und der Pathophysiologie der Thrombose nicht optimal. Diese Antikoagulantien weisen auch mehrere Nachteile auf, die eine optimale Antikoagulation von pädiatrischen Patienten, insbesondere von Neugeborenen und Säuglingen, weiter behindern. Die neuen direkten oralen Antikoagulantien (DOACs), die das Potenzial haben, diese Nachteile zu überwinden, wurden bei Erwachsenen umfassend untersucht und stellen eine valide Alternative zu LMWH und VKA für die Antikoagulation in der Erwachsenenpopulation dar. Derzeit laufen mehrere pädiatrische Studien mit allen zugelassenen DOACs, die spezifische pädiatrische Formulierungen sowie alters- und gewichtsangepasste Dosisrichtlinien enthalten. Erste Ergebnisse der Phase-III-Studien zeigen, dass DOACs zur Behandlung und Prävention thrombotischer Ereignisse bei Kindern mit unterschiedlichen Grundkrankheiten mindestens so effizient und sicher sind wie LMWH und VKA. Dieser Übersichtsartikel fasst die verfügbaren Daten aus abgeschlossenen und laufenden kontrollierten Studien zu DOACs bei Kindern und Jugendlichen zusammen.
\end{abstract}

received

August 9, 2019

accepted after revision

October 7, 2019 (c) 2020 Georg Thieme Verlag KG Stuttgart · New York
DOI https://doi.org/

10.1055/s-0039-3400491. ISSN 0720-9355. 


\section{Introduction}

Venous thromboembolism (VTE) in children and adolescents has dramatically increased over the last two decades. ${ }^{1}$ The rise is mostly due to the increase of improved invasive methods for the diagnosis and treatment of severe and complex medical conditions such as cancer, congenital heart disease, and other congenital malformations involving several organs. ${ }^{1,2}$ In these children, VTE is usually secondary to the use of a central venous catheter. ${ }^{1,2}$ In adolescents, one of the most common cause of VTE is the use of oral contraceptive. ${ }^{3}$

Current standard of care (SOC) for the treatment of VTE in pediatrics includes the use of unfractionated heparin (UFH), low-molecular-weight heparin (LMWH), and vitamin K antagonists (VKA). ${ }^{4,5}$ These anticoagulants have several disadvantages that make anticoagulation in children very challenging, particularly in newborns and infants. Disadvantages include unpredictable pharmacokinetic response, several drug and food interactions, and the need for parenteral administration and frequent monitoring, which is problematic in children with poor venous access. Due to the lack of randomized controlled studies performed in children with these agents, dosage and duration of anticoagulation is extrapolated from adult guidelines; no pediatric, age-specific formulations are available; and all agents are used off-label. ${ }^{4,5}$

Direct oral anticoagulants (DOACs) have proven at least as efficient and safe as SOC for most indications in adults, including treatment and prophylaxis of deep venous thrombosis (DVT), pulmonary embolism, and atrial fibrillation. ${ }^{6}$ DOACs have clearly overcome limitations of SOC in adults and have thus the potential to be of benefit for children, too. Several phase I-III trials are currently ongoing to assess efficacy and safety of DOACs in children and adolescents for several indications.

This review summarizes available data information from completed and ongoing trials on the use of DOACs in the pediatric population.

\section{Direct Thrombin Inhibitors}

\section{Dabigatran Etexilate}

Dabigatran is a 3-((2-[(4-(amino[(E) hexyloxycarbonylimino] methyl)phenylamino) methyl]-1-methyl-1H-benzoimidazole5-carbonyl)pyridine-2-yl-amino) propionic acid ethyl ester compound that specifically and reversibly inhibits thrombin. ${ }^{7}$ Dabigatran is orally administered as the prodrug, dabigatran etexilate, which differs from dabigatran by an ethyl group at the carboxylic acid and a hexyloxycarbonyl side chain at the amidine. ${ }^{8}$ Once absorbed from the gastrointestinal tract, dabigatran etexilate is converted to its active metabolite, dabigatran. ${ }^{9}$ Dabigatran is available in three different pharmaceutical formulations: capsule, pellets, and oral liquid formulation.

Pharmacodynamics (PD) and pharmacokinetics (PK) of dabigatran were investigated in a double-blind, randomized, placebo-controlled study in 40 healthy adult volunteers. ${ }^{10}$ In this study, dabigatran etexilate was rapidly absorbed with peak plasma concentrations of dabigatran reached within 2 hours of administration. Absorption was followed by a rapid distribution/elimination phase and a terminal phase with associated estimated half-lives between 8 and 10 hours with single and 14 and 17 hours with multiple dose administrations (-Table 1). ${ }^{10}$ Further population PK analyses showed that renal function has the most important, clinically relevant impact on dabigatran exposure. ${ }^{11,12}$

\section{Preclinical Pediatric Studies}

The anticoagulant effect of dabigatran in children was first assessed in vitro using pooled plasma sample from healthy children aged birth to $<1,1$ to $<5,5$ to $<10,10$ to $<17$ years, and adults. ${ }^{13}$ Plasma samples were spiked with increasing concentrations of dabigatran and the effect tested in five coagulation assays (prothrombin time [PT], activated partial thromboplastin time [aPTT], diluted thrombin time [dTT], ecarin clotting time [ECT], and thrombin time [TT]). The coagulation assay response to dabigatran for all of the tests was similar in pediatric plasma compared with adult plasma. The PT values were relatively insensitive, but displayed a linear response to increasing dabigatran concentrations. The aPTT was moderately sensitive to increasing dabigatran concentrations with approximately threefold prolongation over baseline at the highest concentration, although the response was not linear. The TT, dTT, and ECT were linearly correlated with dabigatran concentrations; however, the ECT and TT were overly sensitive. In the overall hemostasis potential assay, which quantifies the plasma capacity to generate a fibrin clot, increasing dabigatran concentrations delayed the initiation of clot formation and reduced the time to $50 \%$ clot lysis. The responses to initiation of clot formation and clot lysis were consistent across all pediatric groups and comparable to responses in adults. ${ }^{13}$

\section{Pediatric Dosing Regimen}

Optimal dosing regimen for clinical studies of dabigatran in children was estimated from adult regimens using the Hayton model, which applies to renally eliminated drugs. ${ }^{14}$ Taking into consideration the maturation and growth of the renal function, this model estimates pediatric dosing regimens by adjusting adult doses to the age and weight of the child. ${ }^{14}$ Based on this equation, an age- and weight-adjusted nomogram for different weight ranges was established.

\section{Clinical Pediatric Studies}

Several phase Ila studies assessed pharmacokinetics, safety, and tolerability of dabigatran capsules and oral liquid formulation in children (-Table 2). ${ }^{15-19}$ In one study, nine adolescents aged 12 to 18 years received dabigatran capsules at a dose of $1.71( \pm 10 \%) \mathrm{mg} / \mathrm{kg}$ followed by $2.14( \pm 10 \%)$ $\mathrm{mg} / \mathrm{kg}$ twice daily for 3 days. ${ }^{16}$ No patients had bleeding events, deaths, or drug-related serious adverse events. Two patients developed dyspepsia. The dabigatran PK/PD relationship observed in these adolescent patients was similar to that in adult patients. ${ }^{16}$ In a second study, six patients aged 1 to 2 years (mean age, 1.4 years) and nine patients aged 2 to 12 years (mean age, 5.2 years) were treated with a single dose of dabigatran oral liquid formulation. Three other infants received dabigatran twice daily for 3 days. ${ }^{17}$ No patients 
Table 1 Pharmacologic characteristics of direct oral anticoagulants

\begin{tabular}{|c|c|c|c|c|c|}
\hline \multirow[t]{2}{*}{ Characteristic } & \multirow{2}{*}{$\begin{array}{l}\begin{array}{l}\text { Direct } \\
\text { thrombin } \\
\text { inhibitor }\end{array} \\
\text { Dabigatran }\end{array}$} & \multicolumn{4}{|l|}{ Direct FXa inhibitors } \\
\hline & & Apixaban & Betrixaban & Edoxaban & Rivaroxaban \\
\hline Oral bioavailability, \% & $3-7$ & 52.3 & 34 & 62 & $66-100$ \\
\hline Plasma protein binding, \% & 35 & 87 & 60 & 55 & $92-95$ \\
\hline Renal excretion, \% & 80 & 27 & 17.8 & 50 & 50 \\
\hline \multicolumn{6}{|l|}{ Median $\mathrm{T}_{\max }, \mathrm{h}$} \\
\hline Single dose & $1.25-1.5$ & $1.5-1.8^{\mathrm{a}} / 2.5-3.3^{\mathrm{b}}$ & $3-4$ & $1.0-1.5$ & $0.5-0.6^{\mathrm{a}} / 1.5-3^{\mathrm{b}}$ \\
\hline Multiple dose & 1.5 & & & $1.0-3.5$ & \\
\hline \multicolumn{6}{|l|}{ Mean $\mathrm{t}_{1 / 2}, \mathrm{~h}$} \\
\hline Single dose & $7-9$ & $3.6-6.8^{\mathrm{a}} / 11.1-26.8^{\mathrm{b}}$ & $19-27$ & $5.79-10.7$ & $3.24-4.15^{\mathrm{a}} / 7-17^{\mathrm{b}}$ \\
\hline Multiple dose & $14-17$ & & & $8.75-10.4$ & \\
\hline \multicolumn{6}{|l|}{ Interactions } \\
\hline \multicolumn{6}{|l|}{ P-gp substrate } \\
\hline Inducers & $\begin{array}{l}\text { Decrease } \\
\text { exposure }\end{array}$ & $\begin{array}{l}\text { Decrease } \\
\text { exposure }\end{array}$ & $\begin{array}{l}\text { Decrease } \\
\text { exposure }\end{array}$ & Not relevant & None \\
\hline Inhibitors & $\begin{array}{l}\text { Increase } \\
\text { exposure }\end{array}$ & $\begin{array}{l}\text { Increase } \\
\text { exposure }\end{array}$ & $\begin{array}{l}\text { Increase } \\
\text { exposure }\end{array}$ & $\begin{array}{l}\text { Increase } \\
\text { exposure }\end{array}$ & $\begin{array}{l}\text { Increase } \\
\text { exposure }\end{array}$ \\
\hline \multicolumn{6}{|l|}{ CYP3A4 substrate } \\
\hline Inducers & None & Decrease exposure & None & None & Decrease exposure \\
\hline Inhibitors & None & Increase exposure & None & None & Increase exposure \\
\hline
\end{tabular}

Abbreviations: $\mathrm{t}_{1 / 2}$, half-life; $\mathrm{T}_{\max }$, time to peak plasma concentration; P-gp, P-glycoprotein; CYP, cytochrome P450.

${ }^{a}$ Oral solution.

bTablet.

showed drug-related adverse events, and the PK profile was similar to adults and adolescents. ${ }^{17}$ In a third phase Ila study, eight infants at a mean age of 88.6 days (range, 41-169 days) received a single dose of dabigatran oral liquid formulation. ${ }^{18}$ There were no treatment-related adverse events, no deaths, and no treatment discontinuations. The PK/PD relationships were consistent with the observed profiles in adults and older children. ${ }^{18}$

Interim results of two phase III trials on dabigatran in children were presented at the Annual Meeting of the International Society on Thrombosis and Haemostasis (ISTH), July 6 to 19,2019 , in Melbourne. ${ }^{20,21}$ In the open-label, randomized, active-controlled, multicenter, phase IIb/III trial (DIVERSITY study), 234 children aged 12 to $<18,2$ to $<12$, and 0 to $<2$ years with confirmed diagnosis of VTE and initially treated with UFH or LMWH were randomized (2:1) to dabigatran (capsules, pellets, or oral liquid solution) twice a day or SOC and treated for 3 months. Results of this study indicate that dabigatran is noninferior to SOC in terms of efficacy and safety, and demonstrate the appropriateness of the age- and bodyweight-adjusted dosing algorithm for dabigatran to use in children aged between 0 and $<18$ years $(-$ Table 2$) .{ }^{20}$ In the open-label, single-arm prospective cohort, phase III trial, 203 children aged 12 to $<18,2$ to $<12$, and 0 to $<2$ years with VTE, who were treated with SOC for $\geq 3$ months or completed study treatment in the DIVERSITY study, and had an unresolved clinical risk factor requiring further anticoagulation, were treated with dabigatran for a maximal duration of 12 months. Results of this study indicate that dabigatran has a favorable safety profile in children with persistent VTE risk factors. Few children developed recurrent VTE and few children experienced major bleeding events and/or clinically relevant nonmajor bleeding. ${ }^{21}$ In both studies, dabigatran PK/PD relationships were comparable to previous adult data $\left(-\right.$ Table 2) ${ }^{20,21}$ Further studies on dabigatran in the pediatric population are depicted in -Table $2 .{ }^{15}$

\section{Direct Factor Xa Inhibitors}

\section{Apixaban}

Apixaban is a 1-(4-methoxyphenyl)-7-oxo-6-(4-(2-oxopiperidin-1-yl)phenyl)-4,5,6,7-tetrahydro-1H-pyrazolo[3,4-c]pyridine-3-carboxamide compound with potent, reversible, and highly selective inhibitory activity against coagulation FXa. ${ }^{22}$ Apixaban inhibits free and clot-bound FXa, as well as prothrombinase activity. ${ }^{23}$ Apixaban is available in two different pharmaceutical formulations: tablet and oral solution.

In healthy adult subjects, peak plasma levels of apixaban after a single ascending oral dose were observed at 1.5 to 1.8 hours for the oral solution $(0.5,1.0$, and $2.5 \mathrm{mg})$ and at 2.5 to 3.3 hours for the tablet form $(5,10,25$, and $50 \mathrm{mg}) .{ }^{24}$ The half-life of apixaban was 4.3 to 6.8 hours when administered 


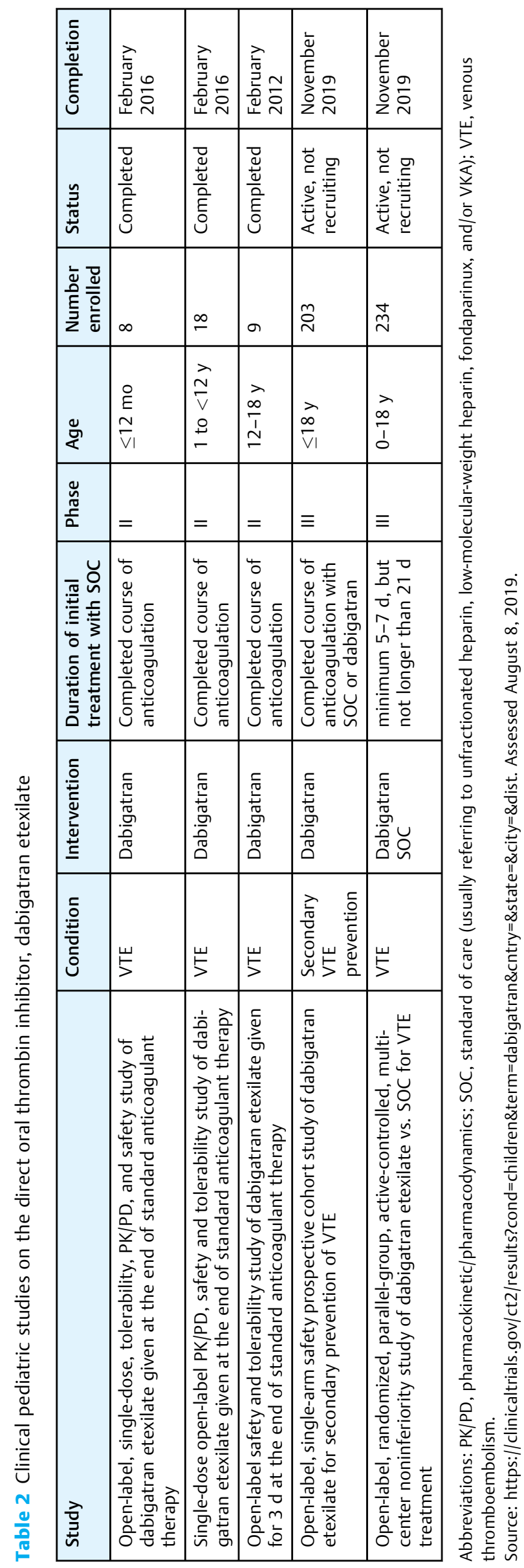

as an oral solution and 11 to 26.8 hours when administered in tablet form (-Table 1$){ }^{24}$

\section{Preclinical Pediatric Studies}

Yetman et al. performed in vitro assays to explore the potential effect of apixaban in the pediatric population using umbilical cord, children, and adult plasma samples spiked with apixaban concentrations of 30 and $110 \mathrm{ng} / \mathrm{mL}^{25}$ Both apixaban concentrations were expected to correspond with peak and trough apixaban concentrations following administration of 2.5 or $5 \mathrm{mg}$ twice daily. ${ }^{25}$ In this study, apixaban demonstrated consistent concentration-related FXa inhibition across all age groups. However, FXa inhibition with apixaban $110 \mathrm{ng} / \mathrm{mL}$ was greater in plasma from children aged 6 months or younger than in plasma from adults. ${ }^{25}$

\section{Clinical Pediatric Studies}

The PK/PD profile of a single-dose apixaban is currently investigated in a phase I study on 44 pediatric patients at risk for a venous or arterial thrombotic disorder. ${ }^{26}$ Further studies on apixaban in the pediatric population are depicted in -Table $3 .^{26}$

\section{Betrixaban}

Betrixaban is anthranilamide-based compound 1,N-(5chloropyridin-2-yl)-2-(4-(N,N-dimethylcarbamimidoyl)benzamido)benzamide with potent FXa inhibitory activity. ${ }^{27}$

At a dose of $80 \mathrm{mg}$, betrixaban is rapidly absorbed and reaches plasma concentration peaks after 3 to 4 hours. ${ }^{28}$ The half-life of betrixaban ranges between 19 and 27 hours $(- \text { Table } 1)^{28}$

Ongoing pediatric studies on betrixaban are listed in -Table $3 .^{29}$

\section{Edoxaban}

Edoxaban is a N-(5-chloropyridin-2-yl)-N'-[(1S,2R,4S)-4-(N, $\mathrm{N}$-dimethylcarbamoyl)-2-(5-methyl-4,5,6,7-tetrahydrothiazolo[5,4-c]pyridine-2-carboxamido)-cyclohexyl]ethanediamide p-toluenesulfonate monohydrate compound that is highly specific and directly inhibits FXa activity. ${ }^{30}$ Edoxaban is available in two different pharmaceutical formulations: tablet and oral suspension.

In healthy adult subjects, peak plasma levels of edoxaban were observed at 1.0 to 1.5 hours after a single ascending oral dose $(10,30,60,90,120$, and $150 \mathrm{mg}) .{ }^{31}$ The half-life of edoxaban ranged from 5.79 to 10.7 hours ( - Table 1 ). ${ }^{31}$ Overall, increasing edoxaban dose resulted in consistent and predictable plasma concentrations. ${ }^{31}$

\section{Preclinical Pediatric Studies}

Sinegre et al. compared the hemostatic response and coagulation assay results in plasma samples from adults and children of different age spiked in vitro with specific concentrations of edoxaban. ${ }^{32}$ In this study, edoxaban anti-FXa activity accurately reflected plasma levels in both children and adults, and the in vitro effects were similar at all ages, with the exception of children younger than 2 years in whom the anticoagulant effect was increased. ${ }^{32}$ 


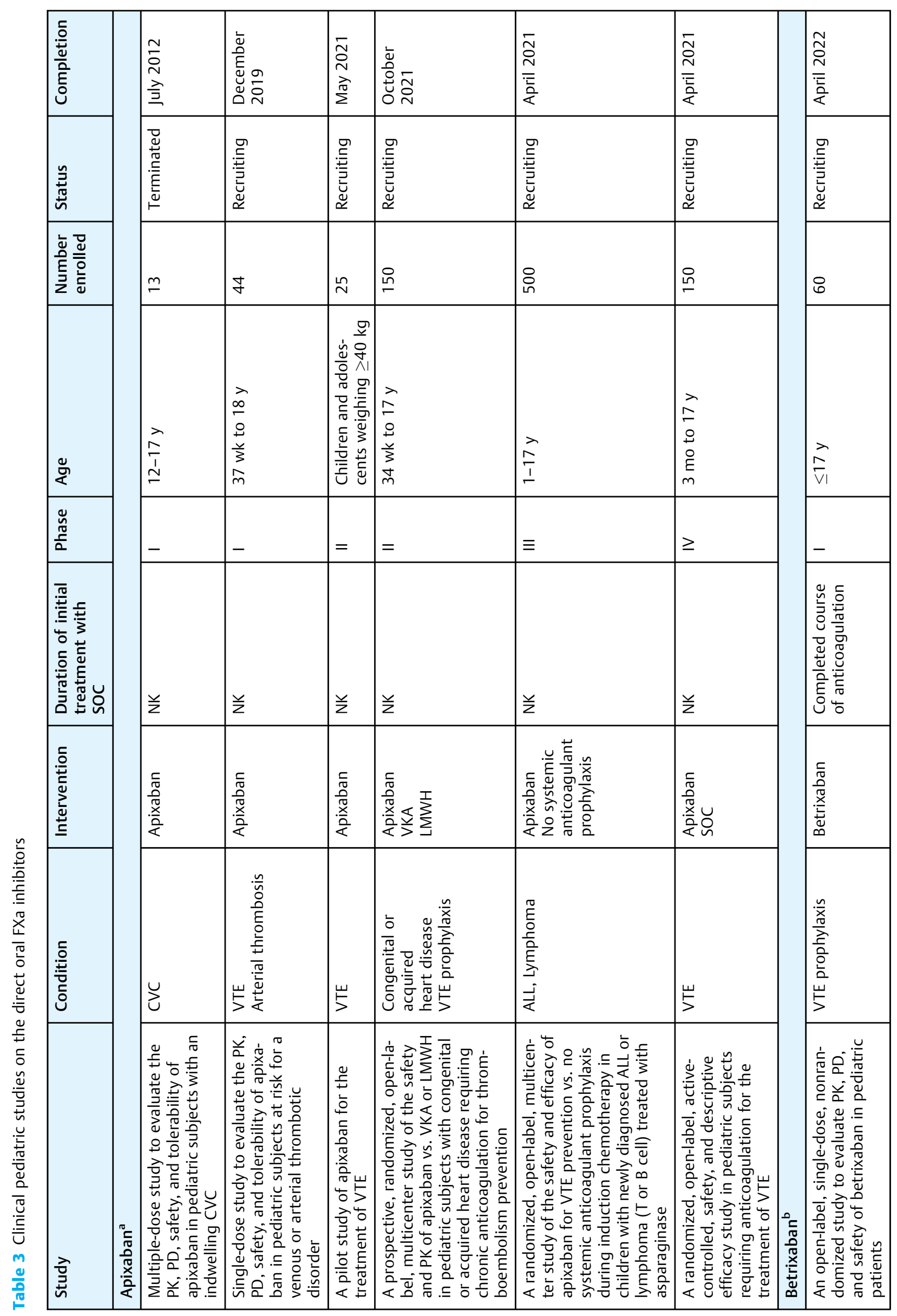




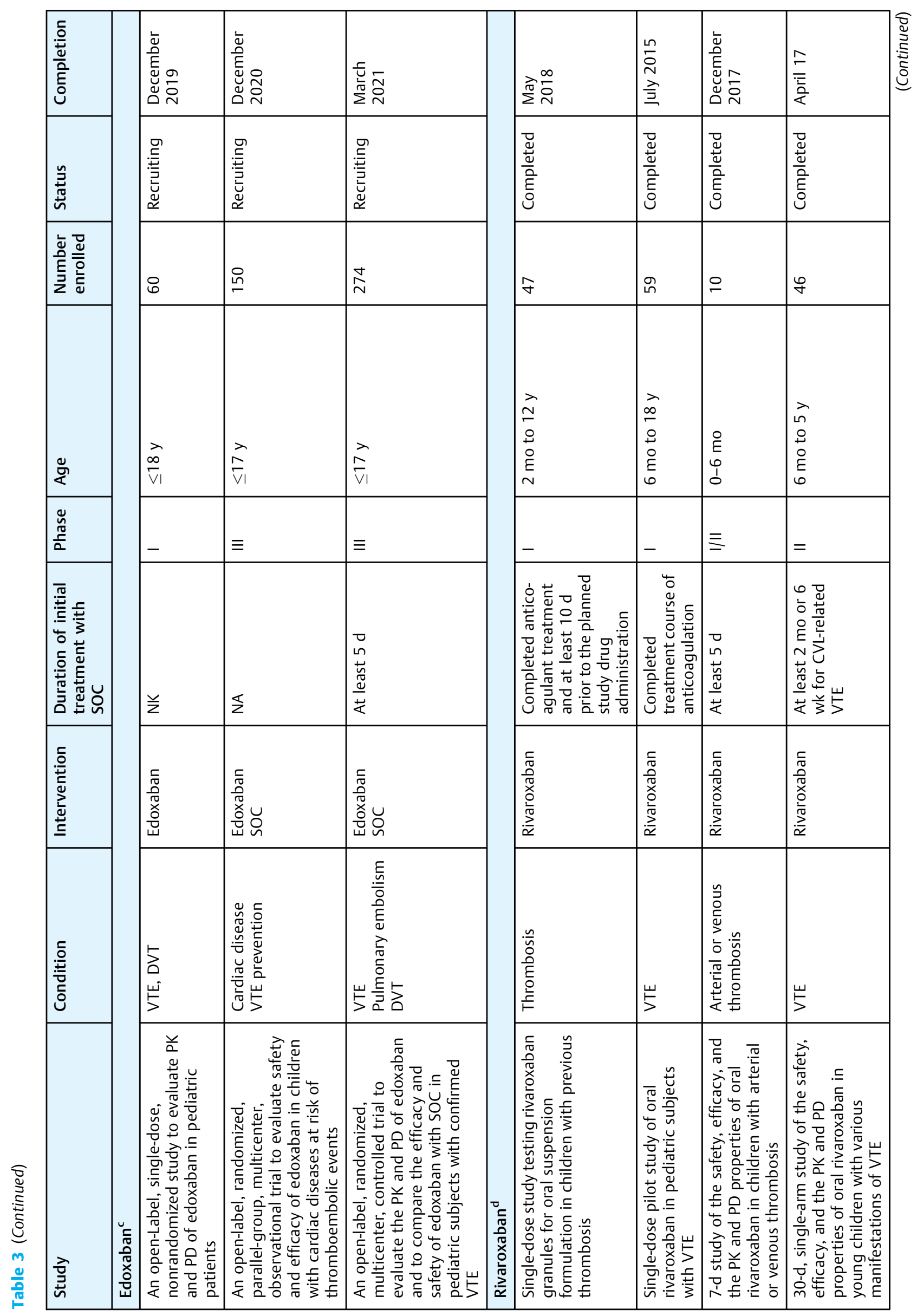


70 DOACs in Children Albisetti

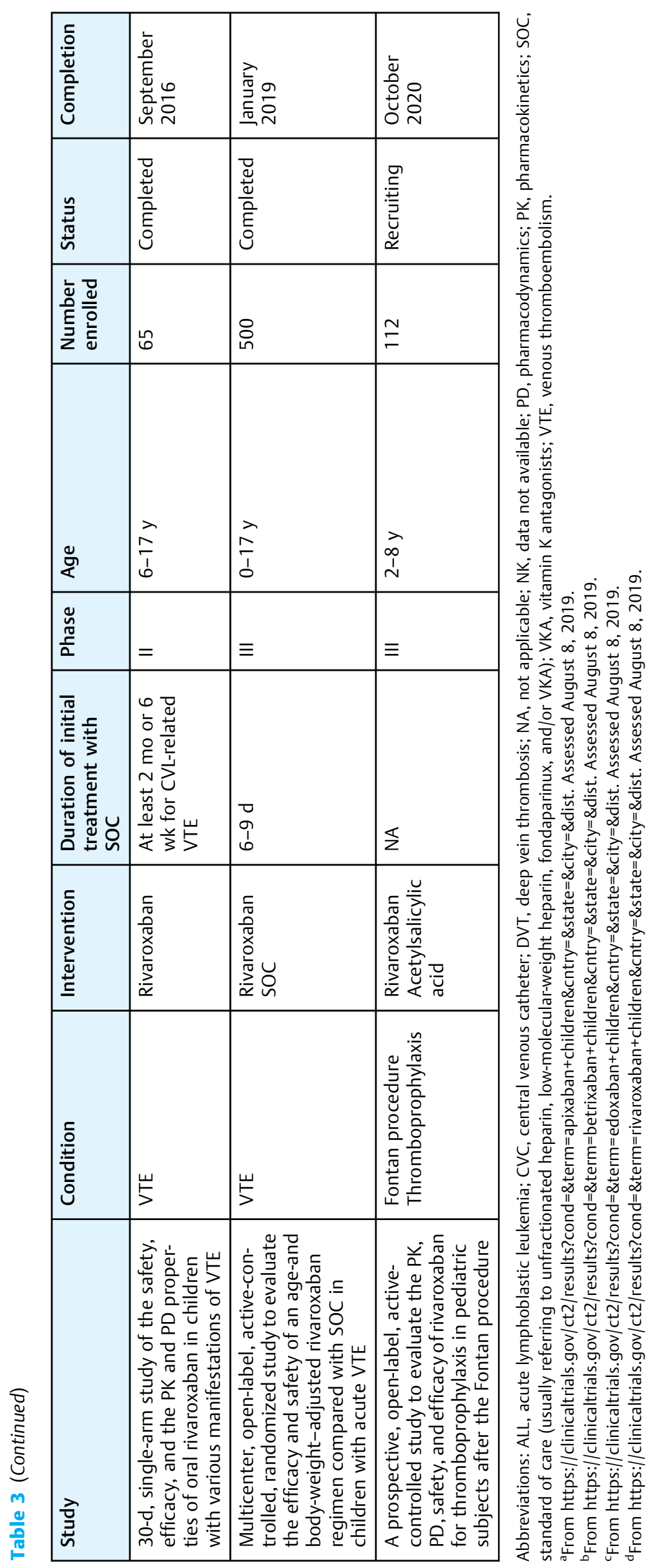

Hämostaseologie Vol. 40 No. 1/2020 
The PK/PD profile of a single-dose edoxaban is currently investigated in a phase I study on 60 pediatric patients aged 0 to 18 years requiring anticoagulant therapy. ${ }^{33}$ Further studies on edoxaban in the pediatric population are depicted in -Table $3^{33}$

\section{Rivaroxaban}

Rivaroxaban is a 5-Chloro-N-(\{(5S)-2-oxo-3-[4-(3-oxomorpholin-4-yl)phenyl]-1,3-oxazolidin-5-yl\}methyl)thiophene2-carboxamide compound with a highly potent and selective direct FXa inhibitory activity. ${ }^{34}$ Rivaroxaban is available in two different pharmaceutical formulations: tablet and oral suspension.

PK/PD profiles of rivaroxaban were first investigated in a single-center, randomized, placebo-controlled study in 108 healthy adult volunteers. ${ }^{35}$ In this study, peak plasma levels of rivaroxaban after a single escalating oral dose were observed at 0.5 to 0.6 hours for the oral solution $(5,10 \mathrm{mg})$ and at 1.5 to 3.0 hours for the tablet form $(1.5,5,10,20,40$, and $80 \mathrm{mg}) .{ }^{36}$ The half-life of rivaroxaban was 3.24 to 4.15 hours when administered as an oral solution. For rivaroxaban tablets at doses greater than $10 \mathrm{mg}$, the half-lives ranged from 7 to 17 hours ( - Table 1 ). ${ }^{35}$

\section{Preclinical Pediatric Studies}

Two studies investigated the age-related anticoagulant effect of rivaroxaban in vitro. ${ }^{36,37}$ In both studies, plasma pools from neonates, children aged 28 days to 23 months, 2 to 6 years, 7 to 11 years, 12 to 16 years, and adults were spiked with increasing concentrations of rivaroxaban (0-500 $\mathrm{ng} / \mathrm{mL}$ ). While rivaroxaban caused a significant increase in the clotting time (PT and aPTT) as well as an increase in lag time (as measured by thrombin generation) in neonates, no significant differences in rivaroxaban effect was observed across the older pediatric age groups when compared with adults. Overall, rivaroxaban demonstrated a predictable and a dose-dependent PK profile in all age groups. ${ }^{36,37}$

\section{Pediatric Dosing Regimen}

To assess the optimal dosing regimen for clinical studies of rivaroxaban in children, a physiologically based PK model for rivaroxaban doses of 10 and $20 \mathrm{mg}$ in adults was developed. ${ }^{38}$ This model was subsequently scaled to the pediatric population (0-18 years) by including anthropometric and physiological information, age-dependent clearance, and age-dependent protein binding. ${ }^{38}$ The body-weight-related dosing regimen led to a large overlap of the simulated plasma PK parameters for all age ranges with the values obtained in the corresponding adult reference simulation. However, PK values in infants and preschool children (body weight: $<40 \mathrm{~kg}$ ) were lower than the $90 \%$ confidence interval threshold of the adult reference model, indicating that in these groups increased doses would be required to achieve the same plasma levels as in adults. ${ }^{38}$

\section{Clinical Pediatric Studies}

The PK of a single rivaroxaban dose in children using population PK modeling was assessed in a phase I study. ${ }^{39,40}$ In this study, two rivaroxaban dose levels equivalent to adult doses of rivaroxaban 10 and $20 \mathrm{mg}$, and two different formulations (tablet and oral suspension), were tested in 59 children aged 0.5 to 18 years who had completed treatment for VTE. ${ }^{39,40}$ The observed plasma concentration-time profiles in all subjects receiving body-weight-adjusted doses were mostly within the $90 \%$ prediction interval, irrespective of dose or formulation. ${ }^{39}$ The PD assessment based on PT and aPTT demonstrated that the anticoagulant effect of rivaroxaban was not affected by development hemostasis (-Table 3 ). ${ }^{40}$

Three phase II studies were performed to confirm or adapt the predicted body-weight-adjusted rivaroxaban regimens from the phase I study in 93 children (10 children younger than 6 months; 15 children aged 6 months to 1 year; 25 children aged $2-5$ years; 32 children aged $6-11$ years; and 11 children aged $12-17$ years). ${ }^{41}$ Therapeutic rivaroxaban exposures with once-daily dosing in children with bodyweights of at least $30 \mathrm{~kg}$ and with twice-daily dosing in children with bodyweights of at least $20 \mathrm{~kg}$ and less than $30 \mathrm{~kg}$ were confirmed. However, children with low body weights $(<20 \mathrm{~kg}$, particularly $<12 \mathrm{~kg}$ ) showed low or subtherapeutic exposure. From these results, rivaroxaban dosages to be adopted for the phase III studies were increased to twice-daily administrations in those with a body weight of at least $12 \mathrm{~kg}$ but less than $20 \mathrm{~kg}$ and three times daily administrations in those weighing less than $12 \mathrm{~kg} .^{41}$ None of the children had a major bleed, and four (4\%) of these children had a clinically relevant non, major bleed (three children aged 12-17 years with menorrhagia and one child aged $6-11$ years with gingival bleeding). No symptomatic recurrent VTE was observed. Of 75 patients having repeat imaging, the thrombotic burden was resolved in 24 (32\%), improved in 43 (57\%), and unchanged in $8(11 \%)$ patients. No patient deteriorated. ${ }^{41}$

Results of a phase III study comparing the efficacy and safety of rivaroxaban with standard anticoagulants for the treatment of acute VTE in children aged from birth to 17 years were presented at the Annual Meeting of the ISTH, July 6 to 19, 2019 , in Melbourne. ${ }^{42}$ In this study, 500 children were randomized to receive open-label rivaroxaban in tablet or suspension form in body-weight-adjusted $20 \mathrm{mg}$ equivalent dose regimens or a standard anticoagulant. Children $<12 \mathrm{~kg}$ body weight were given rivaroxaban three times a day, children between 12 and $30 \mathrm{~kg}$ body weight two times a day, and children $>30 \mathrm{~kg}$ body weight once a day. The main treatment period was 3 months, with the exception of 1 month for children younger than 2 years with a catheter-related thrombosis. Results of this study indicate that children with VTE treated with rivaroxaban showed a low recurrence risk and a reduced thrombotic burden without increased bleeding compared with standard anticoagulants (- Table 3 ). ${ }^{42,43}$ Further studies on rivaroxaban in the pediatric population are listed in - Table $3 .^{43}$

\section{Concluding Remarks}

This is an exciting moment for the pediatric hematology community. Several well-designed, controlled trials providing PK/PD, efficacy, and safety data on DOACs in children are ongoing and in part completed. First data from these studies 
are very promising, indicating that DOACs have consistent $\mathrm{PK} / \mathrm{PD}$ relationships and may show at least comparable efficacy and safety as LMWH and VKA over all pediatric age groups. These studies will help establishing evidencebased guidelines for the treatment and prevention of thromboembolic events in children and adolescents with various underlying conditions in a very near future. Nevertheless, study data from children and adolescents fulfilling inclusion criteria may not necessarily apply for all pediatric patients developing VTE in the daily clinical life. This is, for example, especially true for severely ill newborns and infants or for unstable children at intensive care units who are at increased risk of bleeding. For this reason, collection of real-life data providing insights on the use of DOACs in difficult clinical situations not covered by the studies will be extremely important.

\section{Conflict of Interest}

Dr. Albisetti report research support from Boehringer Ingelheim and Bayer, and advisory board activities for Boehringer Ingelheim and Daiichi Sankyo.

\section{References}

1 Raffini L, Huang YS, Witmer C, Feudtner C. Dramatic increase in venous thromboembolism in children's hospitals in the United States from 2001 to 2007. Pediatrics 2009;124(04):1001-1008

2 Mahajerin A, Branchford BR, Amankwah EK, et al. Hospitalassociated venous thromboembolism in pediatrics: a systematic review and meta-analysis of risk factors and risk-assessment models. Haematologica 2015;100(08):1045-1050

3 Trenor CC III, Chung RJ, Michelson AD, et al. Hormonal contraception and thrombotic risk: a multidisciplinary approach. Pediatrics 2011;127(02):347-357

4 Monagle P, Chan AKC, Goldenberg NA, et al. Antithrombotic therapy in neonates and children: Antithrombotic Therapy and Prevention of Thrombosis, 9th ed: American College of Chest Physicians Evidence-Based Clinical Practice Guidelines. Chest 2012;141(2, Suppl):e737S-e801S

5 Monagle P, Cuello CA, Augustine C, et al. American Society of Hematology 2018 guidelines for management of venous thromboembolism: treatment of pediatric venous thromboembolism. Blood Adv 2018;2(22):3292-3316

6 Khachatryan T, Hauschild C, Hoff J, et al. Review of direct oral anticoagulants and guide for effective drug utilization. Am J Cardiovasc Drugs 2019. Doi: 10.1007/s40256-019-00344-6. [Epub ahead of print]

7 Hauel NH, Nar H, Priepke H, Ries U, Stassen JM, Wienen W. Structure-based design of novel potent nonpeptide thrombin inhibitors. J Med Chem 2002;45(09):1757-1766

8 Eriksson BI, Smith H, Yasothan U, Kirkpatrick P. Dabigatran etexilate. Nat Rev Drug Discov 2008;7(07):557-558

9 Blech S, Ebner T, Ludwig-Schwellinger E, Stangier J, Roth W. The metabolism and disposition of the oral direct thrombin inhibitor, dabigatran, in humans. Drug Metab Dispos 2008;36(02):386-399

10 Stangier J, Rathgen K, Stähle H, Gansser D, Roth W. The pharmacokinetics, pharmacodynamics and tolerability of dabigatran etexilate, a new oral direct thrombin inhibitor, in healthy male subjects. Br J Clin Pharmacol 2007;64(03):292-303

11 Liesenfeld KH, Lehr T, Dansirikul C, et al. Population pharmacokinetic analysis of the oral thrombin inhibitor dabigatran etexilate in patients with non-valvular atrial fibrillation from the RE-LY trial. J Thromb Haemost 2011;9(11):2168-2175
12 Dansirikul C, Lehr T, Liesenfeld KH, Haertter S, Staab A. A combined pharmacometric analysis of dabigatran etexilate in healthy volunteers and patients with atrial fibrillation or undergoing orthopaedic surgery. Thromb Haemost 2012;107(04):775-785

13 Dietrich K, Stang L, van Ryn J, Mitchell LG. Assessing the anticoagulant effect of dabigatran in children: an in vitro study. Thromb Res 2015;135(04):630-635

14 Hayton WL. Maturation and growth of renal function: dosing renally cleared drugs in children. AAPS PharmSci 2000;2(01):E3

15 U.S. National Library of Medicine. Available at: https:// clinicaltrials.gov/ct2/results? cond=children\&term=dabigatran\&cntry $=\&$ state $=\&$ city $=\& d i s t$. Assessed August 8, 2019

16 Halton JM, Lehr T, Cronin L, et al. Safety, tolerability and clinical pharmacology of dabigatran etexilate in adolescents. An openlabel phase Ila study. Thromb Haemost 2016;116(03):461-471

17 Halton JML, Albisetti M, Biss B, et al. Phase Ila study of dabigatran etexilate in children with venous thrombosis: pharmacokinetics, safety, and tolerability. J Thromb Haemost 2017;15(11):2147-2157

18 Halton JML, Picard AC, Harper R, et al. Pharmacokinetics, pharmacodynamics, safety and tolerability of dabigatran etexilate oral liquid formulation in infants with venous thromboembolism. Thromb Haemost 2017;117(11):2168-2175

19 Maas H, Gropper S, Huang F, et al. Anticoagulant effects of dabigatran in paediatric patients compared with adults: combined data from three paediatric clinical trials. Thromb Haemost 2018;118(09):1625-1636

20 Albisetti M, Brandao L, Bomgaars L, et al. Efficacy and safety of dabigatran etexilate for treatment of venous thromboembolism in paediatric patients - results of the DIVERSITY trial. Abstract presented at the Annual Meeting of the International Society on Thrombosis and Haemostasis (ISTH); July 6-19, 2019; Melbourne, Australia

21 Brandao L, Albisetti M, Halton J, et al. Safety of dabigatran for secondary prevention of venous thromboembolism in paediatric patient. Abstract presented at the Annual Meeting of the International Society on Thrombosis and Haemostasis (ISTH); July 6-19, 2019; Melbourne, Australia

22 Pinto DJ, Orwat MJ, Koch S, et al. Discovery of 1-(4-methoxyphenyl)-7-oxo-6-(4-(2-oxopiperidin-1-yl)phenyl)-4,5,6,7-tetrahydro-1H-pyrazolo[3,4-c]pyridine-3-carboxamide (apixaban, BMS-562247), a highly potent, selective, efficacious, and orally bioavailable inhibitor of blood coagulation factor Xa. J Med Chem 2007;50(22):5339-5356

23 Byon W, Garonzik S, Boyd RA, Frost CE. Apixaban: a clinical pharmacokinetic and pharmacodynamic review. Clin Pharmacokinet 2019;58(10):1265-1279

24 Frost C, Wang J, Nepal S, et al. Apixaban, an oral, direct factor Xa inhibitor: single dose safety, pharmacokinetics, pharmacodynamics and food effect in healthy subjects. Br J Clin Pharmacol 2013;75(02):476-487

25 Yetman RJ, Barrett YC, Wang Z, et al. Apixaban pharmacodynamic activity in umbilical cord, paediatric, and adult plasma. Thromb Haemost 2017;117(08):1518-1527

26 https://clinicaltrials.gov/ct2/results? cond=\&term=apixaban+children\&cntry $=\&$ state $=\&$ city $=\&$ dist. Assessed August 8, 2019

27 Zhang P, Huang W, Wang L, et al. Discovery of betrixaban (PRT054021), N-(5-chloropyridin-2-yl)-2-(4-(N,N-dimethylcarbamimidoyl)benzamido)-5-methoxybenzamide, a highly potent, selective, and orally efficacious factor Xa inhibitor. Bioorg Med Chem Lett 2009;19(08):2179-2185

28 Huisman MV, Klok FA. Pharmacological properties of betrixaban. Eur Heart J Suppl 2018;20(Suppl E):E12-E15

29 https://clinicaltrials.gov/ct2/results?cond=\&term=betrixaban+children\&cntry $=\&$ state $=\&$ city $=\&$ dist. Assessed August 8, 2019

30 Furugohri T, Isobe K, Honda Y, et al. DU-176b, a potent and orally active factor Xa inhibitor: in vitro and in vivo pharmacological profiles. J Thromb Haemost 2008;6(09):1542-1549 
31 Ogata K, Mendell-Harary J, Tachibana M, et al. Clinical safety, tolerability, pharmacokinetics, and pharmacodynamics of the novel factor Xa inhibitor edoxaban in healthy volunteers. J Clin Pharmacol 2010;50(07):743-753

32 Sinegre T, Zlobecki M, Doré E, Pereira B, Grèze V, Lebreton A. In vitro assessment of edoxaban anticoagulant effect in pediatric plasma. Thromb Res 2019;178:112-118

33 https://clinicaltrials.gov/ct2/results?cond=\&term=edoxaban+children\&cntry $=\&$ state $=\&$ city $=\&$ dist. Assessed August 8, 2019

34 Roehrig S, Straub A, Pohlmann J, et al. Discovery of the novel antithrombotic agent 5-chloro-N-((5S)-2-oxo-3- [4-(3-oxomorpholin-4-yl)phenyl]-1,3-oxazolidin-5-ylmethyl)thiophene- 2-carboxamide (BAY 59-7939): an oral, direct factor Xa inhibitor. J Med Chem 2005;48(19):5900-5908

35 Kubitza D, Becka M, Voith B, Zuehlsdorf M, Wensing G. Safety, pharmacodynamics, and pharmacokinetics of single doses of BAY 59-7939, an oral, direct factor Xa inhibitor. Clin Pharmacol Ther 2005;78(04):412-421

36 Attard C, Monagle P, Kubitza D, Ignjatovic V. The in vitro anticoagulant effect of rivaroxaban in children. Thromb Res 2012;130 (05):804-807

37 Attard C, Monagle P, Kubitza D, Ignjatovic V. The in-vitro anticoagulant effect of rivaroxaban in neonates. Blood Coagul Fibrinolysis 2014;25(03):237-240
38 Willmann S, Becker C, Burghaus R, et al. Development of a paediatric population-based model of the pharmacokinetics of rivaroxaban. Clin Pharmacokinet 2014;53(01):89-102

39 Willmann S, Thelen K, Kubitza D, et al. Pharmacokinetics of rivaroxaban in children using physiologically based and population pharmacokinetic modelling: an EINSTEIN-Jr phase I study. Thromb J 2018;4:16:32

40 Kubitza D, Willmann S, Becka M, et al. Exploratory evaluation of pharmacodynamics, pharmacokinetics and safety of rivaroxaban in children and adolescents: an EINSTEIN-Jr phase I study. Thromb J 2018;16:31

41 Monagle P, Lensing AWA, Thelen K, et al; EINSTEIN-Jr Phase 2 Investigators. Bodyweight-adjusted rivaroxaban for children with venous thromboembolism (EINSTEIN-Jr): results from three multicentre, single-arm, phase 2 studies. Lancet Haematol 2019;6 (10):e500-e509

42 Male C, Lensing A, Kubitza D, et al. Rivaroxaban for the treatment of acute venous thromboembolism in children. Abstract presented at the Annual Meeting of the International Society on Thrombosis and Haemostasis (ISTH); July 6-19, 2019; Melbourne, Australia

43 https://clinicaltrials.gov/ct2/results?cond=\&term=rivaroxaban+children\&cntry=\&state=\&city=\&dist. Assessed August 8, 2019 